\title{
Climate Change Induced Adaptation Strategies by Paddy Farmers: Special Emphasis on Socio Economic Insights
}

\author{
H. M. L. Herath ${ }^{1}$ and Krishnal Thirumarpan ${ }^{1 *}$ \\ Received: $1^{\text {st }}$ June 2016 / Accepted: $3^{\text {rd }}$ November 2016
}

\begin{abstract}
Climate change is inevitable and will continue into next century. Since the agricultural sector in Sri Lanka is most vulnerable to climate change, a thorough understanding of adaptive measures is important for formulating effective policy decisions. This study provides an overview of the status of climate change and adaptation in the paddy sector in Anuradhapura District. Proportionate sampling was done and total of 100 households were studied. $36 \%$ of the farmers had the education up to tertiary level. $72 \%$ of respondents heard the term "climate change". The relative importance of adaptation strategies to climate change was analyzed and found that increased use by insuring farm against risk was ranked first and thus most important, among farmers' adaptive strategies to climate change. Use of supplementary reservoir for water storage, shift to shorter cycle crop varieties and planting improved rice varieties were identified as the second-ranked adaptation strategy. The shifting of harvesting period was ranked as the last one.

The shifting of harvesting period was ranked as the last one. T test results showed a significant difference $(p<0.01)$ in the total amount paddy production among those who had chosen to use traditional and cultural knowledge and those who didn't choose. It is recommended that government must ensure that a climate change sensitive program is established in paddy cultivation that can be effective in future climate change scenarios.
\end{abstract}

Keywords: Adaptation, adaptation strategy index, Climate change

\section{INTRODUCTION}

Climate change is a global challenge and a serious threat requiring urgent response from all sectors. The potential and widespread effects of climate change on both humans and the environment makes it an important concern for the agricultural sector. The Intergovernmental Panel on Climate Change (IPCC, 2007) has identified South Asia as having the highest proportion of 'highly vulnerable' sectors in the Asia sub-regions. The Intergovernmental Panel on Climate Change (IPCC) in its fourth assessment report observed that, warming of climate system is now unequivocal, as is now evident from observations of increases in global average air and ocean temperatures, widespread melting of snow and ice, and rising global sea level (Kumar and Balasubramanian, 2010). Sri Lanka's climate has also been changing for a couple of decades. As a result, the expected rainfall may not come at the expected time with correct amount and intensity, whereas more rainfall may be received when it is not really necessary and annual mean air temperature anomalies have also shown significant increasing trends during the recent few decades in Sri Lanka (Punyawardena, 2009). In Sri Lanka agriculture is the most vulnerable sector to droughts (Chithranayana and Punyawardena, 2013).

The major rice growing areas are in the Dry and Intermediate Zones in Sri Lanka. The 
Dry and Intermediate Zones are the most vulnerable to drought, with the districts of Jaffna, Killinochchi, Batticaloa, Polonnaruwa, Anuradhapura and Kurunegala having the highest probability of experiencing drought. The Dry Zone, where nearly $70 \%$ of the paddy is cultivated, is already showing an increasing number of consecutive dry days due to rainfall variability. Although about two thirds of the paddy is cultivated under irrigation, crop losses due to drought and shortage of irrigation water are of frequent occurrence (Ministry of Environment, 2011). The growth and yield of the paddy grown in these regions are largely determined by the variability of rainfall either positive or negative anomaly. This may cause serious socioeconomic impacts and imperil the future food security of the country (Ministry of Environment, 2011).

The implementation of adaptive measures will greatly help to reduce the adverse impacts of climate change and the farmers will be ready to cope with uncertainties brought about by climate change. (Chithranayana and Punyawardena, 2013). According to Esham and Garforth (2013) in Sri Lanka, the adverse impact of climate change on agricultural production could be minimized by applying suitable adaptation strategies such as modifying their crop choices and crop calendars, in response to changes in rainfall patterns and average temperatures. They further said that in some areas, climateinduced changes in the beginning and ending dates of the wet season will require that farmers modify rice planting and harvest dates, with potential implications for the number of crops produced each year, rice yields, and aggregate production. Representative Agricultural Pathways (RAPs) ensemble an overall narrative description of a plausible future development pathway and key variables with qualitative storylines and quantitative trends. (Rosenzweig et al, 2013). According to Zubair et al (2014), in Sri Lankan context RAPs were constructed in consultation with different stakeholders and the salient projected changes in the coming decade included rice productivity shall adversely affected due to deterioration of soil fertility, extreme weather events, climate change and phasing out of fertilizer subsidies (without adaptation).and technology developments in the rice sector with high yielding, flood and drought tolerant cultivars, and improved crop management practices shall improve the productivity.

Recently observation and quick assessments indicated the changes in climate in Anuradhapura district. 340 Acres of paddy lands were damaged by drought, during the 2014/15 Maha season in Nuwaragampalatha East DS division in Anuradhapura District. According to Vulnerability Mapping, Thalawa Divisional Secretariat division in Anuradhapura District was ranked as number 7 in all Island (Ministry of Environment,2010).

In a study to identify the risk on drought for crop production in Anuradhapura district, daily rainfall data over 35 years in seven rain gauge stations were analyzed. Among all the stations, both highest mean annual rainfall of 1488.5 $\mathrm{mm}$ and annual dependable rainfall of 1276.6 $\mathrm{mm}$ were recorded in Padaviya (The mean annual rainfall of dry zone was $1750 \mathrm{~mm}$ ). The minimum rainfall values of $1087.6 \mathrm{~mm}$ and $903.1 \mathrm{~mm}$ were noted in Nochchiyagama respectively and the average number of dry weeks in the district was 25 (out of 26) for Yala season and 19 (out of 26) for Maha season (Kumari and Navaratne, 2006).

To ensure the sustainability of livelihoods of paddy farmers in Anuradhapura district and to form policy and planning for the future, a better understanding of farmer's perceptions regarding climate change and current adaptation strategies to climate change are very important. With this the following objectives were formulated. To study the socio economic status of paddy farmers in Anuradhapura district, to study the 
perception of paddy farmers on climate change, and to estimate the Strategies those were adopted in overcoming the effects of adverse climatic conditions.

\section{METERIALS AND METHODS}

Anuradhapura district is the largest Administrative District and covered 10.9\% out of total land area of Sri Lanka. (District Secretariat, Anuradhapura 2015). This study was conducted in five Divisional Secretariat Divisions in Anuradhapura District. These five D. S. Divisions were selected based on the data of high vulnerability areas to climate change. Proportionate sampling was done and 35, 30, 10, 10 and 15 samples were collected from Thambuththegama, Mihinthale, Nuwaragampalatha East, Nuwaragampalatha and Thalawa D.S Division respectively. The target group of the survey was paddy farmers and they were interviewed at their door house. Primary data were taken from personal interviews with household head using a questionnaire. Data on climate change in Anuradhapura district, data on maximum and minimum temperature, and average rainfall in Anuradhapura districts were collected from Department of Meteorology, Sri Lanka. All data were carefully examined for their accuracy and consistency

\section{Data analysis}

To identify the adaptive strategies which held relative importance over others, an adaptation index was estimated, as measured by the formula presented below. Farmers were asked to assess different adaptation strategies by using the four-point rating scale to rate the importance of each strategy to their agricultural enterprises. The relative importance of adaptation strategies to climate change was calculated based on the following index formula.

$\mathrm{ASI}=\mathrm{AS} n \times 0+\mathrm{AS} l \times 1+\mathrm{AS} m \times 2+\mathrm{AS} h \times 3$
ASI = Adaptation Strategy Index

$\mathrm{AS} n=$ Frequency of farmers rating adaptation strategy as having no importance

$\mathrm{AS} l=$ Frequency of farmers rating adaptation strategy as having low importance

$\mathrm{AS} m=$ Frequency of farmers rating adaptation strategy as having moderate importance

$\mathrm{AS} h=$ Frequency of farmers rating adaptation strategy as having high importance

Descriptive statistics, frequency analysis and $\mathrm{T}$ test were done for questionnaire. Trend analysis for average annual minimum temperature, maximum temperature and annual rainfall were carried out for the entire data set of 10 years starting from 2004 to 2014.

\section{RESULTS AND DISCUSSION}

\section{Socioeconomic Characteristics of Paddy Farmers}

Average experience in paddy farming was 25.7 years. $79 \%$ of farmers were male and the rest were female. The total income of household was Rs. 34510.00 per month with the standard deviation of 26727.39 .

\section{Education Level of the Paddy Farmers}

Results revealed that $36 \%$ of the farmers had the education up to tertiary level and only $2 \%$ didn't attend school (Figure 01). In a study by Allison et al. (2009) found that vulnerability and adaptation of a nation to climate change impact depends on level of education of its citizens.

\section{Perception of changes in the climate variables}

In the study area most of the farmers (72\%) heard about the term "climate change". And also $28 \%$ don't have any idea about climate change. 


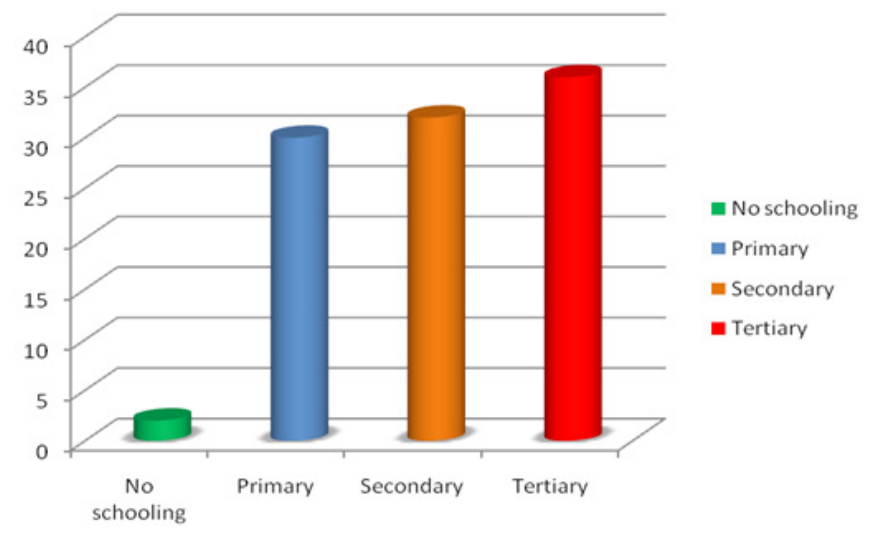

Figure 01: Education Level of the Paddy Farmers

\section{Perceptions on Changes in the State of Climate by the paddy Farmers.}

Results from the study showed that paddy farmers had various, mostly negative, perceptions on the state of their local climate during that period and seemed to perceive many changes to have taken place in their local climate (Table 01). The most notable and commonly cited changes included the following: the amount of rainfall was sometimes decreasing or increasing side (49\%); the temperature of the areas was on the increasing or decreasing side (49\%); and changes in the onset of rainfall in which farmers feel that onset is now abnormally late (44\%).

It was also important to note that $54 \%$ of all respondents perceived rainfall being abnormally increasing these years than before. Very few farmers $(2 \%)$ said that rainfall was constant during this period. As for temperature, $53 \%$ perceived that it has been fluctuating, while 41 $\%$ felt that it has been increasing (Table 02).

\section{Trend of Rainfall and Temperature in Anuradhapura district during last decade}

An increasing trend was observed in annual rainfall from 2004-2014 in Anuradhapura district. During 2005, 2009 and the 2013 annual rainfall was lowest. From 2013 to 2014 the annual rainfall increased drastically (Figure 02).
Change of maximum and minimum temperatures were shown in the Figures. 03 and Figure 04. Maximum temperature was increasing and the minimum temperature was decreasing. In 2012 the maximum temperature was highest $(33.16$ ${ }^{\circ} \mathrm{C}$ ) and the minimum temperature was lowest in 2004 of $23.82^{\circ} \mathrm{C}$. In rice, extreme maximum temperature is of particular importance during flowering which usually lasts two to three weeks. Exposure to high temperature for a few hours can greatly reduce pollen viability and, therefore, cause yield loss. Spikelet sterility is greatly increased at temperatures higher than $35{ }^{\circ} \mathrm{C}$ (Osada et al., 1973). And the effects of increasing minimum temperature on rice growth and yield are less understood than the effects of extremely high day temperatures on spikelet sterility (Kukla and Karl, 1993)

\section{Motivating factors for adaptation strategies}

Results of the study presented in Table 03 showing a general overview of the factors reported to have motivated paddy farmers to change farming practices. Apart from the factors, sources and types of adaptation related information for the farmers are also presented and discussed. 
Table 01: Perceptions on Changes in the State of Climate by the paddy Farmers

\begin{tabular}{lc}
\hline \multicolumn{1}{c}{ Perceptions } & Percentage of respondents \\
\hline Change in amount of rainfall during main rain season & 47 \\
Shift in the timing of the onset of rain in the main season & 44 \\
Temperature of the area decreasing/ increasing & 49 \\
Rainfall of the area increasing/ decreasing & 49 \\
Increase/ decrease in recurrences of floods & 43 \\
Increase/ decrease in recurrence of droughts & 39 \\
Other (specify) & 26 \\
\hline
\end{tabular}

(Multiple Response)

Table 02: Perceptions on the trend of rainfall and temperature for the past 10 years

\begin{tabular}{cc}
\hline Trend of rainfall for the past 10 years & Percentage \\
\hline Increasing & 54 \\
Decreasing & 0 \\
Fluctuating & 44 \\
Constant & 2 \\
Don't know & 0 \\
Trend of temperature for the past 10 years & 41 \\
Increasing & 0 \\
Decreasing & 53 \\
Fluctuating & 5 \\
Constant & 1 \\
Don't know & 5 \\
\hline
\end{tabular}

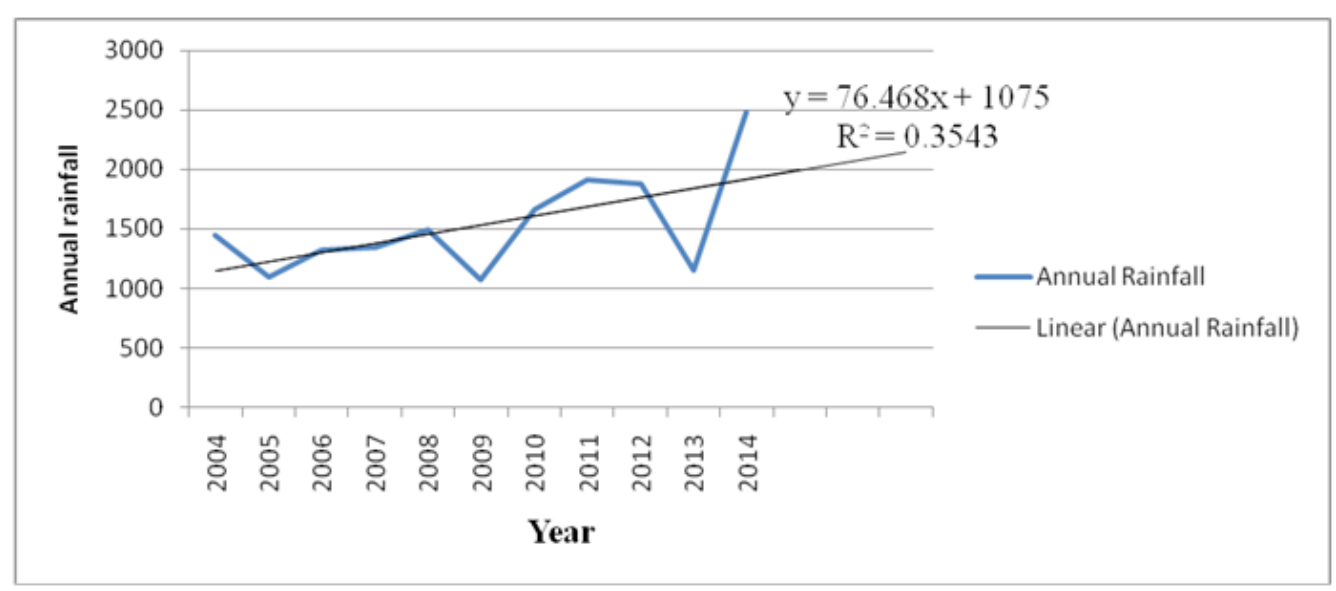

Source: Meteorological Agency, Sri Lanka

Figure 02: Trend of annual rainfall during Last decade (2004 -2014) 


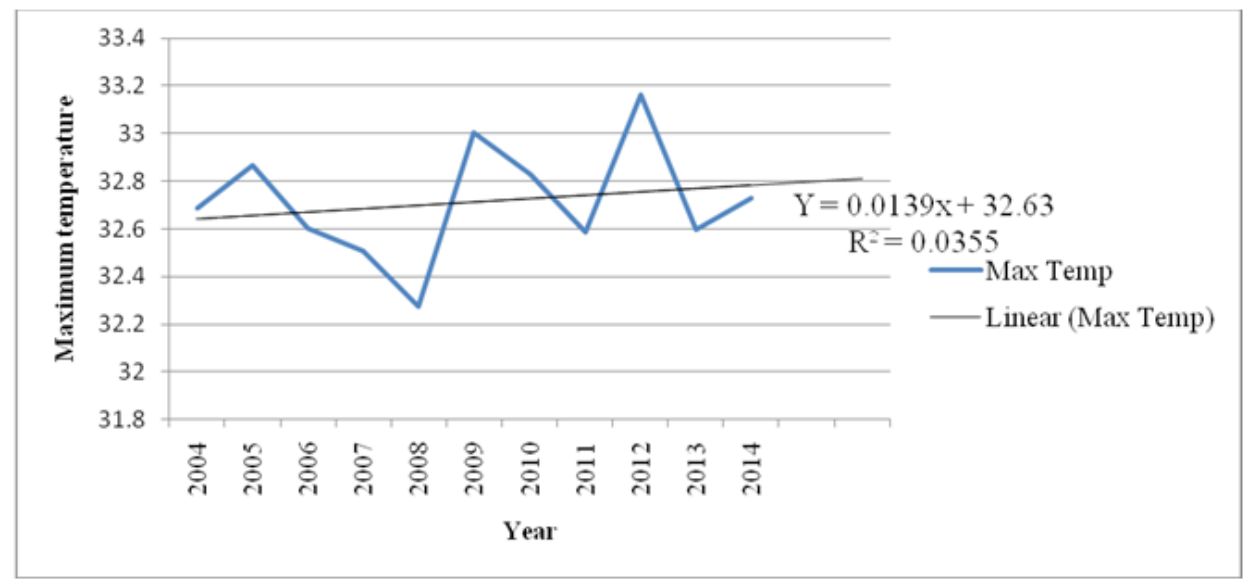

Source: Meteorological Agency, Sri Lanka

Figure 03: Trend of maximum temperature during Last decade (2004 -2014)

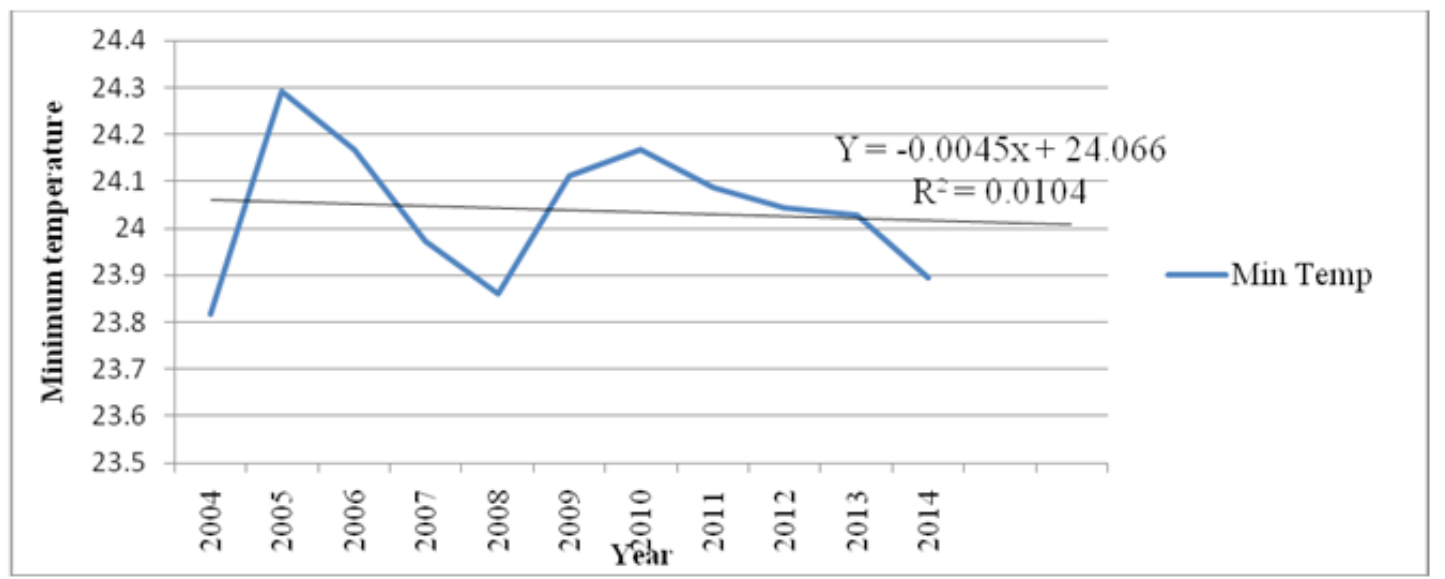

Source: Meteorological Agency, Sri Lanka

Figure 04: Trend of minimum temperature during Last decade (2004 -2014)

Table 03: Possible Factors for motivation

\begin{tabular}{lc}
\hline \multicolumn{1}{c}{ Possible Factors } & Percentage \\
\hline Negative climate change effects & 87 \\
Financial capital & 11 \\
High living costs & 9 \\
Household size & 40 \\
Others Influence & 11 \\
\hline
\end{tabular}

(Multiple Response)

Factors that motivated to follow the adaptation farming practices was negative effects of climate strategies

Results showed that main factor strongly played a role in motivating farmers to change their change and was mainly recurrent because $87 \%$ of respondents were found to believe that the negative effects of climate change motivating them to change their farming practices in all 
the 5 DS divisions. The remaining four factors, namely, household size (40\%), financial capital (11\%), high living costs $(9 \%)$, influence of others $(11 \%)$ such as neighbors, implied that their level of influence in motivating farmers to change farming practices was lower.

The mostly cited negative effects of changes in the local climate were late onset of rainfall in almost all seasons, rainfall becoming very short in terms of its cycle and rainfall having higher distribution per season, much as it may be not adequate in terms of amount in some of the seasons, and also not well distributed to allow farmers to get good harvests.

In addition to negative effects of climate change, influence of high living costs was mostly found to be higher to motivate farmers to follow adaptation strategies.

\section{Percentage of Respondents heard about the term "Adaptation to climate change}

The result showed most farmers $(55 \%)$ heard the term adaptation to climate change, and the rest of them didn't hear that term. And also most said the adaptation to climate change mean the "changing the cultivation methods" and "changing their farming practices".

\section{Respondent's knowledge about climate change adaptation strategies}

A large number of farmers had adequate knowledge of climate change and its coping strategies (Table 04). As evident in majority of the farmers provided a correct response to the knowledge check statements on climate change and its adaptation strategies. The local people had knowledge of climate change adaptation and they were expected to adopt them on their farms in order to mitigate climate change effects. However, $57 \%$ of the respondents did not know that climate change can cause loss of soil fertility. They, therefore, need enlightenment on this to help them maintain soil fertility. Similarly, $47 \%$ of the respondents did not know that climate change causes invasion of pests and diseases on farms. This could be attributed to the fact that they have not experienced pests' invasion on their farms during climate change.

Majority of the respondents $(62 \%)$ responded that extreme change in weather didn't affect health conditions of farm families and $61 \%$ responded that Climate change can negatively affect rice production.

\section{Climate change adaptation strategies used by paddy farmers.}

The results from the analysis of the quantitative data showed that paddy farmers were making various changes in their farming practices, but everyone didn't use same adaptation strategies

(Table 05).However all the respondents used at least one or more adaptation strategy for paddy farming. The identified practices included planting improved rice varieties such as new paddy that offer farmers higher yields instead of the traditional breeds, shifting to shorter cycle crop varieties, which can take short periods of time like three months from planting to harvesting; shifting to drought tolerant crops and varieties; Use of supplementary reservoir for water storage; and insuring farm against risk.

Table 05 revealed that the majority $(55 \%)$ of the respondents used supplementary reservoir for water storage. Early warning information was utilized by $48 \%$ of the respondents. Early warning systems, which inform the communities of the planting date in the study areas about upcoming extreme weather events assisted in adjustments to climate change variability (Eisenack and Stecker, 2010). 
Table 04: The Knowledge questions

\begin{tabular}{lc}
\hline \multicolumn{1}{c}{ Knowledge questions } & Percentage \\
\hline Climate change can negatively affect rice production & 61 \\
Climate change can reduce soil fertility & 43 \\
Climate change increases invasion of pests and diseases & 53 \\
Sudden break in rainfall cannot affect rice production & 23 \\
$\begin{array}{l}\text { Climate change may cause extreme change in weather condition which can } \\
\text { cause sickness among farm families }\end{array}$ & 38 \\
Avoidance of flood prone areas can reduce paddy losses & 70 \\
\hline
\end{tabular}

(Multiple Response)

Table 05: Climate change adaptation strategies used by respondents.

\begin{tabular}{lc}
\hline \multicolumn{1}{c}{ Adaptation Strategy } & Frequency (\%) \\
\hline Planting improved rice varieties & 28 \\
Planting of drought resistant rice varieties & 17 \\
Shifting planting dates & 31 \\
Shifting of harvesting period & 24 \\
By insuring farm against risk & 50 \\
Avoidance of flood prone areas & 44 \\
Seeking early warning information on climate change & 48 \\
Use of supplementary reservoir for water storage & 55 \\
Shift to shorter cycle crop varieties & 49 \\
\hline
\end{tabular}

(Multiple Response)

$31 \%$ of the respondents have shifted the planting date until the weather becomes favourable. 44 $\%$ of the respondents avoided flood prone areas as compared to other land uses. This could be due to differences in their socio-economic status. Resource poor farmers could not just move to another location without being helped financially. Planting improved rice varieties only used by $28 \%$ and $17 \%$ used planting of drought resistant rice varieties as adaptation strategies to climate change.

\section{Relative importance of different adaptation strategies}

Increased use of insuring farm against risk was ranked first and thus most important, among farmers' adaptive strategies to climate change and $50 \%$ of the farmers ranked it as highly important (Table 06). Agricultural insurance policies protect the farmer against these unforeseen climate changes by way of indemnification. Use of supplementary reservoir for water storage, shift to shorter cycle crop varieties and planting improved rice varieties were identified as the second-ranked adaptation strategy. As lack of water was the main problem during drought period in Anuradhapura district there should some alternative for supplementary reservoirs for irrigation. Flooding is a major stress constraint to rice production, especially in rain fed lowland areas. Flooding also a cause of yield fluctuations because of erratic rainfall 
patterns and poor drainage of many rice fields. Developing varieties resistant against drought, flood, pest and diseases would be more suitable to overcome the climate change problems. Planting short term varieties was becoming more popular throughout the country because of its economic returns. The shifting of harvesting period was ranked as the last one where only $24 \%$ ranked it as highly important adaptation strategy.

Sources and needs of Adaptation related Information

Access to climate and adaptation related information is one of the important aspects that may serve to explain adaptive capacity of an individual, a community and so forth (Phillips, 2003) There was also a need to get the type of information they would wish to be informed in order to enhance their adaptive capacity in the future. In other words, it was essential to know the media through which paddy farmers in this area depending on more for accessing climate and adaptation related information and their information preference.

Farmers were depended on more number of sources (Table 07). Television (54\%) ranked the first source of information to paddy farmers. While traditional and cultural knowledge including forecasting the second most dependable source of information and scored $48 \%$, the role of agriculture extension officers in this area were $45 \%$ only.

Results showed that most of the farmers sought pieces of information on the following aspects: Agricultural practices, knowledge and information about climate change (56\%); scientific information about climate change (52\%); society Information about climate change $(52 \%)$; and strategic and policy information about climate change (52\%) (Table 08).

$82 \%$ of the respondents thought that these climate changes in the local climate will continue in the future, and the rest felt that these changes will not continue in future.

Table 06: Ranked order of the adaptation strategies to climate change.

\begin{tabular}{|c|c|c|c|c|c|c|}
\hline \multirow{2}{*}{ Adaptation Strategy } & \multicolumn{4}{|c|}{ Importance to Your Farm } & \multirow{2}{*}{$\begin{array}{l}\text { Adaptation } \\
\text { Strategy } \\
\text { Index }\end{array}$} & \multirow{2}{*}{ Rank } \\
\hline & High & Medium & Low & No & & \\
\hline By insuring farm against risk & 50 & 29 & 17 & 4 & 225 & 1 \\
\hline Use of supplementary reservoir for water storage & 54 & 17 & 25 & 4 & 221 & 2 \\
\hline Shift to shorter cycle crop varieties & 48 & 29 & 19 & 3 & 221 & 2 \\
\hline Planting improved rice varieties & 30 & 62 & 7 & 1 & 221 & 2 \\
\hline Shifting planting dates & 31 & 56 & 13 & 0 & 218 & 5 \\
\hline Seeking early warning information on climate change & 49 & 23 & 19 & 9 & 212 & 6 \\
\hline Avoidance of flood prone areas & 43 & 27 & 21 & 9 & 204 & 7 \\
\hline Planting of drought resistant rice varieties & 16 & 72 & 12 & 0 & 204 & 7 \\
\hline Shifting of harvesting period & 24 & 19 & 37 & 20 & 147 & 9 \\
\hline
\end{tabular}


Table 07: Information sources

\begin{tabular}{lc}
\hline \multicolumn{1}{c}{ Source } & Frequency (\%) \\
\hline Radio & 35 \\
Newspapers & 41 \\
Television & 54 \\
Religious institution & 18 \\
Agriculture Extension Officers & 45 \\
Researchers & 41 \\
Traditional and cultural knowledge including forecasting & 48 \\
NGOs & 34 \\
Meteorological Agency forecast information & 35 \\
\hline
\end{tabular}

(Multiple Response)

Table 08: Type of information

\begin{tabular}{lc}
\hline \multicolumn{1}{c}{ Type of information } & Frequency (\%) \\
\hline Scientific Information about climate change & 52 \\
Agricultural Practices, Knowledge and information about climate change & 56 \\
Economic/Commercial Information about climate change & 40 \\
Society Information about climate change & 52 \\
Strategic and Policy information about climate change & 52 \\
\hline
\end{tabular}

(Multiple Response)

\section{Near Future Adaptation Options}

This section presents near future coping up strategies and adaptation options which, according to paddy farmers' knowledge and experiences, if implemented, will support them to enhance their adaptive capacity and longterm resilience to adverse impacts of climate change and variability (Table 09 ).

Table 09: Future adaptation options
The analysis of data identified three main options each of which had a score of well over $50 \%$ as follows: continue changing agricultural practices in line with the changes in the local climate (59\%); ask for food aid (56\%); promote irrigation using underground water (51\%). Abandon paddy cultivation at the expense of other economic activities had the lowest score $(27 \%)$.

\begin{tabular}{lc}
\hline Abandon paddy cultivation at the expense of other economic activities & 27 \\
Ask for government support like introduction of new and modern adaptation options & 49 \\
Seek to obtain more information, knowledge and education on adaptation to climate change & 40 \\
Promote irrigation using underground water & 51 \\
Ask for food aid & 56 \\
Emigrate from your village to other areas with better conditions & 43 \\
Continue changing agricultural practices in line with the changes in the local climate & 59 \\
\hline Multiple Response) &
\end{tabular}


Policy and Strategic Interventions for long term resilience

The results presents policy and strategic interventions for long term resilience, if implemented, will support them to enhance their adaptive capacity to adverse impacts of climate change and variability (Table10).

The analysis of data revealed four main options each of which had a score of well over $50 \%$ as follows: Develop and introduce new crop varieties to increase the tolerance against climatic conditions (70\%), develop and/or strengthen early warning systems that provide daily weather predictions and seasonal forecasts (66\%), Support to adopt modern irrigation and agricultural related better technologies (62\%), Disseminate local experience and knowledge (53\%). But improving the institutional capacity and efficiency had the lowest score (24\%).

Opinions of paddy farmers to implement adaptation to climate change in Anuradhapura district

The analysis of quantitative data identified four main opinions of the paddy farmers in this area. Most of the farmers (42\%) had the opinion to implement any action to avoid the flooding in the area followed by $38 \%$ had the opinion that the government should take necessary action to repair the tank and cannels. $14 \%$ of the farmers felt that the action should be initiated to supply Mahaweli water for the cultivation and rest of the farmers felt that government support is needed to adaptation to climate change.

\section{T- test result}

Result showed that there was a significant difference $(p<0.01)$ observed in the total amount paddy production, those who had choose to use traditional and cultural knowledge including forecasting and those who didn't choose Table 11.

\section{CONCLUSION AND POLICY RECOMMENDATIONS}

Being heavily dependent on Agriculture, paddy farming in Sri Lanka is particularly vulnerable to climate change. Hence suitable adaptation strategies are important to the changes in climate. This study was conducted mainly to find out the Climate Change Adaptation strategies by Paddy farmers in Anuradhapura district.

\section{Table 10: Policy and Strategic Interventions}

\begin{tabular}{lc}
\hline \multicolumn{1}{c}{ Policy and strategic intervention } & Frequency $(\%)$ \\
\hline Enhance your capacity through education and training & 31 \\
Improve institutional capacity and efficiency & 24 \\
More research and dissemination of research results to farmers & 45 \\
Disseminate local experience and knowledge & 53 \\
$\begin{array}{l}\text { Develop and introduce new crop varieties to increase the tolerance against climatic } \\
\text { conditions }\end{array}$ & 70 \\
Introduce crop insurance & 47 \\
$\begin{array}{l}\text { Support to adopt modern irrigation and agricultural related better technologies } \\
\text { Develop and/or strengthen early warning systems that provide daily weather predictions } \\
\text { and seasonal forecasts }\end{array}$ & 62 \\
(Multiple Response) & 66
\end{tabular}


Table 11: Group statistic

\begin{tabular}{lcccc}
\hline & $\begin{array}{l}\text { Traditional and cultural } \\
\text { knowledge including forecasting }\end{array}$ & No & Mean & Std. Deviation \\
\hline Total amount paddy production & choose & 48 & 2941.67 & 214.211 \\
(Yield (kg/acre) & Not Choose & 52 & 2786.54 & 443.263 \\
\hline
\end{tabular}

Independent samples T-test between Traditional and cultural knowledge including forecasting and Total amount paddy production (Yield (kg/acre)

\begin{tabular}{|c|c|c|c|c|c|c|}
\hline \multicolumn{7}{|c|}{ T-test for Equality of Means } \\
\hline & & $\begin{array}{c}\text { Mean } \\
\text { Difference }\end{array}$ & $\begin{array}{l}\text { Std. Error } \\
\text { Difference }\end{array}$ & $\mathrm{t}$ & $\begin{array}{l}\text { Degrees of } \\
\text { freedom }\end{array}$ & Sig \\
\hline \multirow[t]{2}{*}{$\begin{array}{l}\text { Total amount of } \\
\text { paddy production } \\
\text { (Yield (kg/acre) }\end{array}$} & $\begin{array}{l}\text { Equal variances } \\
\text { assumed }\end{array}$ & 155.13 & 70.56 & 2.19 & 98 & 0.03 \\
\hline & $\begin{array}{l}\text { Equal variances not } \\
\text { assumed }\end{array}$ & 155.28 & 68.81 & 2.26 & 74.87 & 0.02 \\
\hline
\end{tabular}

As Paddy production remains a source of income for rural communities in selected study areas, adaptation to climate change in paddy production by farmers is imperative, as to improve their livelihoods and ensure food security. A better understanding of ongoing adaptation measures and the determinants of adaptation strategies used by the paddy farmers was important to create policies aimed at promoting successful adaptation strategies for the sector.

Results revealed that an increasing trend in annual rainfall from 2004-2014 in Anuradhapura district. From 2013 to 2014 the annual rainfall increased drastically. Maximum temperature was increasing and the minimum temperature was decreasing. In 2012 the maximum temperature was highest $\left(33.16{ }^{\circ} \mathrm{C}\right)$ and the minimum temperature was lowest in 2004 of $23.82{ }^{\circ} \mathrm{C}$.

The main factor in motivating farmers to change their farming practices was negative effects of climate change and was mainly recurrent. Majority of the respondents used supplementary reservoir for water storage as adaptation mechanism. Early warning information was utilized by $48 \%$ of the respondents as an adaptation strategy. Increased use by insuring farm against risk was ranked first and thus most important, among farmers' adaptive strategies to climate change. Use of supplementary reservoir for water storage, shift to shorter cycle crop varieties and planting improved rice varieties were identified as the second-ranked adaptation strategy. The shifting of harvesting period was ranked as the last one.

Main policy and strategic intervention identified by the paddy farmers in the district were to develop and introduce new crop varieties to increase the tolerance against climatic conditions, develop and/or strengthen early warning systems that provide daily weather predictions and seasonal forecasts, Support to adopt modern irrigation and agricultural related better technologies and to disseminate local experience and knowledge.

Based on the results of the study and of IPCC guidelines it is recommended that Agricultural 
adaptation funding is required especially assistance should be targeted toward the most vulnerable paddy farmers. And there should be increased investment in agricultural research with reference to climate change adaptation, and investment in market and climate information as well as disaster preparedness information systems

\section{REFERENCES}

Allison, E. H., Perry, A. L., Badjeck, M.-C., Adger, W. N., Brown, K., Conway, D., Halls, A. S., Pilling, G. M., Reynolds, J. D., Andrew, N. L. \& Dulvy, N. K. (2009). Vulnerability of national economies to the impacts of climate change on fisheries. Fish Fisheries, 10, 173196. DOI: http://dx.doi.org/10.1111/j.1467-2979.2008.00310.x

Chithranayana R.D. \& Punyawardena B.V.R. (2008). Identification of drought prone agroecological regions in Sri Lanka. Journal of the National Science Foundation of Sri Lanka 36: 117-124. DOI: http://dx.doi.org/10.4038/jnsfsr.v36i2.143

Eisenaek, K... Stecker, R.. (2011) A framework for analyzing climate change adaptations as actions. Mitigation and Adaptation Strategies for Global Change (in press). DOI: 10.1007/s1 1027011-9323-9.

Esham, M. and Garforth, C. (2013). Agricultural adaptation to climate change: Insights from a farming community in Sri Lanka. Mitigation Adaptation Strategies Global Change 18, 535-549 DOI: http://dx.doi.org/10.1007/s11027-012-9374-6

IPCC (2007). Climate Change (2007): Impacts, Adaptation and Vulnerability. Contribution of Working Group II to the Fourth Assessment Report of the Intergovernmental Panel on Climate Change. (Eds. M.L. Parry, O.F. Canziani, J.P. Palutikof, van der P.J. Linden \& C.E. Hanson) p. 976. Cambridge University Press, Cambridge, UK. DOI: http://dx.doi. org/10.2134/jeq2008.0015br

Kumar, K.S., and Balasubramanian, I., (2010). Climate Variability and Agricultural Productivity: Case study of rice yields in Northern India. Madras: School of Economics. DOI: http:// dx.doi.org/10.1016/j.agwat.2006.06.009

Kumari, M. K. N. and Navaratne, C M (2006). Drought analysis in relation to crop production: Anuradhapura district. Proceedings of the International Forestry and Environment Symposium. University of Sri Jayewardenepura, Sri Lanka. p 13. DOI: http://dx.doi. org/10.17501/biotech.2016.1103

Kukla, G., and T.R. Karl. (1993). Night-time warming and the greenhouse effect. Environ. Sci. Technol. 27:1468-1474. DOI: http://dx.doi.org/10.1021/es00045a001

Ministry of Environment in Sri Lanka, 2011/2012. National Climate Change Adaptation for Sri Lanka 2011 to 2016. Colombo, Sri Lanka. DOI: http://dx.doi.org/10.4038/jnsfsr.v38i2.2032

Ministry of Environment (MOE), (2010). 'Strengthening Capacity for Climate Change Adaptation Sector Vulnerability Profile: Agriculture and Fisheries', Climate Change Secretariat Sri Lanka, ADB TA 7326 (SRI), Draft, unpublished. DOI: http://dx.doi.org/10.1007/978-94017-1053-4_8 
Osada A, V. Saciplapa, M. Rahong, S. Dhammanuvong, and H. Chakrabandho. (1973). Abnormal occurrence of empty grains of indica rice plants in the dry, hot season in Thailand. Proceedings of the Crop Science Society of Japan 42:103-109. DOI: http://dx.doi.org/10.1626/jcs.42.103

Punyawardena, B.V.R., (2009). A Brief Glimpse at climate change, In: Gunarathne, L.H.P. et al., 2009. Role of Community in Adaptation to the Climate Change Crisis. Stockholm: Swedish Cooperative Centre. DOI: http://dx.doi.org/10.3362/9781780440415.000

Rosenzweig, C., Jones, J., Hatfield, J. W., Antle, J. M., Boote, K. J., Thorburn, P. and Valdivia, R. O. (2013). AgMIPGuide for Regional Integrated Assessments: Handbook of Methods and Procedures. Version 5.1. Available at: http://www.agmip.org/wp content/uploads/2014/07/ AgMIP-Regional-Integrated-Assessment-Handbook-v5.1.pdf. $\quad$ DOI: http://dx.doi. org/10.18411/d-2016-154

Zubair, L., Nissanka, S. P., Weerasinghe, K. D. N., Punyawardhene, B. V. R., Weerakoon, W. M. W.,Wickramagamage, P., Agalawatte, P., Chandrasekera, S. C., Delpitiya, P., Navaratne, C. M., Gunaratna, J., Herath, D. I., Herath, R. M., Karunaratne, A., Ratnayake, S., Samaratunga, P.,Sanmuganathan, K.,Vishwanathan, J.,Wijekoon, E., Weerasinghe,A. K., Yahiya,Z.,Perera ,T.M.R.S.,Gunesekara,A.A.I.,Ratnasekera,H.,Ralapanawe,V.,Seneviratne,G.,andWallach,D. (2014). Modeling the impacts of a variable and changing climate on rice agricultural systems in Sri Lanka for AgMIP. Sri Lanka Project Final Report for AgMIP, Technical Report, Foundation for Environment, Climate and Technology, Kandy, Sri Lanka DOI: http://dx.doi. org/10.1142/9781783265640_0022 